\title{
Genetic differentiation in the Antarctic coastal krill Euphausia crystallorophias
}

\author{
SN Jarman ${ }^{1,2,3}$, NG Elliott ${ }^{2}$, S Nicol ${ }^{3}$ and A McMinn ${ }^{1}$ \\ ${ }^{1}$ Institute of Antarctic and Southern Ocean Studies, University of Tasmania, GPO Box 252-77, Hobart, TAS, 7001, Australia; \\ ${ }^{2}$ CSIRO Marine Research, GPO Box 1538, Hobart, TAS, 7001, Australia; ${ }^{3}$ Australian Antarctic Division, Channel Highway, \\ Kingston, TAS, 7050, Australia
}

The population genetics of the Antarctic neritic krill species Euphausia crystallorophias was examined by nucleotide sequence variation in its mitochondrial DNA. A 616 base pair region of the cytochrome $c$ oxidase subunit I (COI) gene was screened for mutations by single-strand conformational polymorphism (SSCP) combined with restriction digestion. $E$. crystallorophias caught in three different regions of the Antarctic coastline were used - two samples from the Mertz Glacier Polynya and one sample each from the western side of the Antarctic Peninsula and from the Davis Sea. Significant genetic differences between krill samples were ident-

Keywords: crustacea; genetics; krill; population; SSCP; swarm ified. However, the extent of these differences did not correlate with the degree of geographic separation between the sampling sites. This suggests that the genetic structuring may be the result of small-scale differentiation rather than differentiation between resident populations in separate parts of the Southern Ocean. The possibility that genetic differences between samples within a region are as important as differences between regions has implications for other studies of krill population genetics.

Heredity (2002) 88, 280-287. DOI: 10.1038/sj/hdy/6800041

\section{Introduction}

Krill (Malacostraca: Euphausiacea) are pelagic filter-feeding crustaceans. They are an abundant component of the pelagic ecosystem of all oceans. Most krill species have highly discontinuous distributions as a result of their tendency to form dense swarms (Mauchline and Fisher, 1969). Krill play an important role in carbon and energy transfer from the photosynthetic microorganisms on which they predominately feed to the diverse megafauna that prey on them (Mauchline and Fisher, 1969).

Euphausia crystallorophias Holt and Tattersall, 1906, commonly called 'crystal krill' or 'Antarctic coastal krill', is the most southerly krill species. It inhabits the waters of the neritic zone between the Antarctic coast and the continental shelf to about $500 \mathrm{~m}$ depth (Mauchline and Fisher, 1969). E. crystallorophias is the most abundant euphausiid in these waters and is an important food source for diverse coastal predators (Thomas and Green, 1988) including fish (La Mesa et al, 2000), whales (Ichii et al, 1998) and penguins (Ainley et al, 1998; Wienecke et al, 2000). It feeds on planktonic diatoms (Mauchline and Fisher, 1969), bacteria, detritus and other microorganisms (Pakhamov and Perissinotto, 1996) as well as grazing the algal communities that form on the underside of ice floes (Melnikov and Spiridinov, 1996). E. crystallorophias thus forms probably the most important trophic link between

Correspondence: S Jarman, CSIRO Marine Research, GPO Box 1538, Hobart, TAS 7001, Australia.E-mail: Simon.Jarman@marine.csiro.au Received 8 May 2001; accepted 16 November 2001 primary production and the macrofauna of the Antarctic coast.

The population genetics of E. crystallorophias has been investigated previously by Fevolden and Ayala (1981) and by Kühl and Schneppenheim (1985) using allozyme electrophoresis. The first study compared allozyme frequencies in one sample of E. crystallorophias with frequencies for the same enzymes in several samples of Euphausia superba, which is a close relative of E. crystallorophias (Patarnello et al, 1996; Jarman et al, 2000). The comparison in allele frequencies between the two species demonstrated that there is negligible gene flow between them. Kühl and Schenppenheim's study examined allozyme frequency differences between four separate samples of E. crystallorophias and also made a comparison between these samples and samples of E. superba. For 17 loci examined, no significant difference in allele frequency was found between two samples of E. crystallorophias caught on the western side of the Antarctic Peninsula and two samples taken from widely separated positions in the Weddell Sea. A significant departure from genotype frequencies expected under Hardy-Weinberg equilibrium was recorded for only one of the enzymes, GPI. The authors concluded that E. crystallorophias forms a single interbreeding population that is genetically distinct and reproductively isolated from E. superba (Kühl and Schneppenheim, 1985).

Several population genetic studies of krill in recent years have identified genetic differentiation within the subject species. Zane et al (1998) studied the population structure of E. superba with mitochondrial DNA sequencing. Previous studies of this species with allozymes had 
found no significant genetic differentiation between widely separated samples (MacDonald et al, 1986; Fevolden and Schneppenheim, 1989). The mitochondrial DNA study found significant genetic structure in the species and significant pairwise $F_{\text {st }}$ and $\Phi_{\text {st }}$ differences between E. superba collected in the Wedell Sea and near South Georgia, though not between any other pairwise combinations of the four samples (Zane et al, 1998). Mitochondrial DNA variation was also used by Bucklin et al (1997) and by Zane et al (1999) to examine the population genetics of Meganyctiphanes norvegica. This species had also previously been studied with allozymes, which did not detect any population genetic structure (Sundt and Fevolden, 1996), whereas the mitochondrial DNA studies of $M$. norvegica did identify population differentiation. In each case where genetic differentiation was identified the authors suggested that the genetic differences between the samples were caused by restricted gene flow between different parts of each species' range (Bucklin et al, 1997; Zane et al, 1998, 1999).

Biological variation between krill samples caught within one area has been demonstrated previously for the Antarctic krill E. superba (Fevolden and George, 1984; Quentin and Ross, 1984; Watkins et al, 1986, 1990). For example, significant differences were found in length, weight, sex and maturity for krill caught in trawls at adjacent locations in the vicinity of South Georgia (Watkins et al, 1986, 1990). This observation was pursued further by Watkins et al (1990) who found the minimum number of krill samples needed to get a reliable estimate of krill population parameters in a geographic area such as the ocean around South Georgia. For all population parameters assessed, more than 14 samples of 100 individuals are needed to get an unbiased estimate. Temporal variation in population parameters for E. superba has also been demonstrated by Reid et al (1999) who found significant inter-annual variation in mean length of krill in this same region. These studies demonstrate that single samples of krill from one area do not provide a reliable estimate of the population characteristics of krill in that area. The assumption of previous population genetic studies of krill, that single hauls of krill can adequately describe genetic population parameters for a region in space and time, may therefore also be incorrect.

In this study the population genetics of E. crystallorophias is studied with the frequency of mitochondrial DNA haplotypes in different krill samples. DNA sequence variation in the $5^{\prime}$ end of the mitochondrial cytochrome c oxidase subunit I (COI) gene was identified using the single strand conformational polymorphism (SSCP) method (Orita et al, 1989; Hongyo et al, 1993; Sunnucks et al, 2000). Haplotype frequency variation found in four different samples of E. crystallorophias was used to test a null hypothesis of unrestricted gene flow between the populations represented by these samples. The alternative hypothesis that this study was designed to investigate was that genetic differences between populations are caused by restricted gene flow between different regions of the Southern Ocean. The opportunity to test two samples from one region of the Southern Ocean allowed a preliminary investigation of another alternative hypothesis: that genetic differentiation between krill samples is not related to large scale geographic differentiation, but rather to the differentiation between krill swarms.

\section{Materials and methods}

\section{Sample collection}

Euphausia crystallorophias were collected from four locations during 1999. A sample $(n=61)$ was taken from the West Antarctic Peninsula region (66 $53^{\prime} \mathrm{S} 68^{\circ} 55^{\prime} \mathrm{W}$ ) in January 1999 during the austral summer. Two samples $(n=59,47)$ were collected from the Mertz Glacier Polynya $\left(66^{\circ} 23^{\prime} \mathrm{S} 145^{\circ} 54^{\prime} \mathrm{E}\right.$; $\left.66^{\circ} 29^{\prime} \mathrm{S} 146^{\circ} 1^{\prime} \mathrm{E}\right)$ in winter during September 1999. One sample $(n=65)$ was collected from near the Shackelton Ice Shelf in the Davis Sea $\left(65^{\circ} 32^{\prime} \mathrm{S} 107^{\circ} 0^{\prime} \mathrm{E}\right)$ during December 1999 . Each sample is the result of a single, short $(<10 \mathrm{~min})$ net tow and is assumed to be from one krill swarm or a small number of adjacent aggregations. All samples were preserved in $75 \%$ ethanol until required for DNA extraction.

\section{DNA isolation}

A novel DNA purification method was used. About 50 $\mathrm{mg}$ of krill abdominal muscle was placed in a $1.5 \mathrm{ml}$ microcentrifuge tube and homogenised in $400 \mu \mathrm{l}$ of $5 \mathrm{M}$ guanidine thiocyanate, $50 \mathrm{mM}$ Tris $\mathrm{pH} \mathrm{8.0,0.5 \%} \mathrm{Triton}$ X-100 and $0.05 \%$ sodium dodecyl sulfate. This mixture was incubated on a shaking platform at $65^{\circ} \mathrm{C}$ for $2 \mathrm{~h}$ to allow the chaotropic guanidine thiocyanate to denature proteins (Bowtell, 1987; Chomczynski et al, 1997); and the sodium dodecyl sulfate to disentangle them from DNA (Ausubel et al, 1997). Two hundred $\mu \mathrm{l}$ of $5 \mathrm{M} \mathrm{NaCl}$ was added to precipitate proteins (Miller et al, 1988), which were pelleted by centrifugation at $20000 \mathrm{~g}$ for $20 \mathrm{~min}$. The resulting supernatant was poured into a new tube containing $200 \mu \mathrm{l} 0.5 \mu \mathrm{g} / \mu \mathrm{l}$ proteinase $\mathrm{K}$. The solutions were mixed and incubated on a shaking platform at $65^{\circ} \mathrm{C}$ for $2 \mathrm{~h}$. Five hundred $\mu \mathrm{l} 100 \%$ ethanol was added to precipitate nucleic acids, which were pelleted by centrifugation at $20000 \mathrm{~g}$ for $20 \mathrm{~min}$. Most of the contaminating polysaccharides were held in solution at this stage by the $>1 \mathrm{M} \mathrm{NaCl}$ concentration (Fang et al, 1992) and discarded with the supernatant. The precipitated pellet of DNA was washed in $70 \%$ ethanol to remove residual salts, air dried and then dissolved in $100 \mu 10 \mathrm{mM}$ Tris pH 8.0.

\section{Amplification of mitochondrial DNA}

A 616 base pair region of the mitochondrial COI region was amplified with the polymerase chain reaction (PCR) using 'universal' primer HCO (5'-taaacttcagggtgaccaaaaaatca-3') (Folmer et al, 1994) and the species-specific primer EcLCO (5'-ggtgcgtgagctgggatagtggg-3'). EcLCO was designed on the sequence previously reported for a slightly longer segment of the E. crystallorophias mtCOI by Jarman et al (2000) as GenBank accession number AF177183.

Each $20 \mu \mathrm{l}$ PCR contained $100 \mathrm{ng}$ purified E. crystallorophias DNA from one individual krill as a template. The reaction buffer was $50 \mathrm{mM} \mathrm{KCl}, 10 \mathrm{mM}$ Tris- $\mathrm{HCl} \mathrm{pH} 8.9$, $2.5 \mathrm{mM} \mathrm{MgCl}_{2}, 0.1 \%$ Triton X-100. $0.25 \mathrm{mM}$ of each dNTP, 2 units Taq DNA polymerase (Promega) and 10 pmol of each primer were included. The reactions had an initial incubation at $94^{\circ} \mathrm{C}$ for 2 min to denature template DNA, followed by thermal cycling at $94^{\circ} \mathrm{C} 20 \mathrm{sec}, 43^{\circ} \mathrm{C}$ $1 \mathrm{~min}$ and $72^{\circ} \mathrm{C} 1 \mathrm{~min}$ for 40 cycles. A 6-min incubation at $72^{\circ} \mathrm{C}$ followed to finish synthesis of incomplete strands.

\section{SSCP analysis of mtDNA haplotypes}

Ten $\mu$ l of each completed PCR amplification was restriction digested at $37^{\circ} \mathrm{C}$ for $4 \mathrm{~h}$ with endonuclease $\mathrm{RsaI}$ 
(New England Biolabs). The following components were added for this reaction: $1.2 \mu \mathrm{l} 100 \mathrm{mM}$ Bis Tris propane$\mathrm{HCl}, 100 \mathrm{mM} \mathrm{MgCl}_{2}, 10 \mathrm{mM}$ dithiothreitol (New England Biolabs $10 \times$ buffer 1), $0.2 \mu \mathrm{l}$ RsaI (2 units) and $0.6 \mu l \mathrm{H}_{2} \mathrm{O}$. This cut the $665 \mathrm{bp}$ PCR product $(616 \mathrm{bp}$ of amplified krill DNA +49 bp of primers) into two fragments of 303 and $362 \mathrm{bp}$. Two $\mu \mathrm{l}$ of the restriction-digested DNA solution was then added to $10 \mu \mathrm{l}$ of $95 \%$ formamide, $0.25 \%$ xylene cyanol, $0.25 \%$ bromophenol blue, $10 \mathrm{mM} \mathrm{NaOH}$. These mixtures were placed in a $95^{\circ} \mathrm{C}$ heating block for 3 min to denature the DNA and then quickly placed on ice.

The samples were then loaded onto a $200 \mathrm{~mm} \times 170$ $\mathrm{mm} \times 0.75 \mathrm{~mm}$ gel composed of $0.5 \times$ MDE polyacrylamide solution (FMC Bioproducts), $0.6 \times \mathrm{TBE}, 0.1 \%$ TEMED and $0.1 \%$ ammonium persulfate. SSCPs were resolved on this gel by electrophoresis in $0.6 \times$ TBE at 4 $\mathrm{W}$ for $14 \mathrm{~h}$ while the gel was kept at $4^{\circ} \mathrm{C}$ by circulation of chilled water through a chamber adjacent to the gel (BioRad Protean IIxi). Twenty-five samples were run on each gel, with one sample being a reference that was also run on another gel to allow comparisons between gels.

After electrophoresis, one glass plate was removed and $30 \mathrm{ml} 1 \times$ SyBr Gold (Molecular Probes) nucleic acid stain was poured onto the gel. This was left for $20 \mathrm{~min}$ and the gel transferred onto a UV transilluminator. The gel was photographed through a SyBr Gold/Green filter (Molecular Probes) with Polaroid 655 film by exposure for $4 \mathrm{~min}$ at F8 while transilluminated with $300 \mathrm{~nm} \mathrm{UV.}$

\section{Haplotype scoring}

Photonegatives of SSCP gels were used to assign haplotypes for the large and small COI fragments to each krill. Most haplotypes could be assigned easily by eye. Samples not run in adjacent lanes were sometimes compared on an image file taken from the photonegative using NIH image 1.62 software to measure the relative migration of the fragments. If there was doubt about scoring, the sample was run again alongside different samples.

\section{Haplotype sequencing}

Each observed haplotype was sequenced at least once. Any haplotype that occurred more than once was sequenced at least twice to check that the scoring of haplotypes was consistent and to check that each SSCP represented a single DNA sequence. mtCOI haplotypes to be sequenced were selected from their SSCPs. The PCR products for individuals that had lost the RsaI site used in the SSCP assay, so that one fragment remained after restriction digestion, were also sequenced.

Ten $\mu \mathrm{l}$ of PCR amplified DNA that was not restriction digested was separated from the unincorporated primers and other PCR components using the Qiagen Quick Spin PCR purification procedure. Thirty ng of the purified PCR product was used as a template in Big Dye Terminator (ABI) sequencing reactions. The reactions were separated on an ABI 377 automated sequencer.

\section{Data analysis}

The haplotype sequences for each fragment of the COI region and the number of times each individual sequence occurred in each population were the basis for all analyses. A composite haplotype for the entire $616 \mathrm{bp}$ region was assigned to each individual either from its small and large fragment SSCPs or from direct sequencing.
Sequence data were processed with Sequence Navigator (ABI) software. The sequences for the various COI haplotypes were then combined into a single text file and aligned by eye. Each variable site in the COI sequence was checked to see if it altered the translation of the DNA into protein by using GeneJockey software (BioSoft). The mitochondrial DNA genetic code for Drosophila melanogaster was used as it is likely to be the same genetic code found in krill.

Tests for significant departures from selective neutrality of the haplotypes in each population were executed with Arlequin version 2.0 (Schneider et al, 2000). Tajima's test based on ideal non-recombining sequences with infinite sites is appropriate for mitochondrial data (Tajima, 1989). Ewens-Watterson's test for selective neutrality based on ideal populations with an infinite number of alleles (Ewens, 1972; Watterson, 1978) was also applied. In each case 1000 pseudoreplicate datasets were created from the original dataset to use as a null distribution for significance testing.

Analysis of molecular variance (AMOVA, Excoffier et al, 1992) was used to assess the relative contributions of variance in genetic differentiation within and between krill samples. In order to choose a model of DNA substitution for relating the various haplotypes, the haplotype data were imported into PAUP* 4.0b4a (Swofford, 1998). A neighbour-joining (Saitou and Nei, 1987) tree relating the haplotypes was calculated to provide a basis for maximum likelihood (Felsenstein, 1981) estimation of equilibrium base composition, all possible substitution types and the $\alpha$ shape parameter of a discrete gamma distribution of relative substitution rates between sites (Yang, 1994). After choosing an appropriate DNA substitution model and estimating the $\alpha$ parameter for gamma correction, AMOVA calculations were made with Arlequin version 2.0 (Schneider et al, 2000). An overall $\Phi_{\text {st }}$ was calculated as an estimate of between sample variation.

Six pairwise $\Phi_{\text {st }}$ calculations $(m=6)$ were made using Arlequin version 2.0 between all combinations of the four populations analysed to assess how much of the among sample variation was attributable to each sample. The same model of DNA substitution used for the AMOVA was applied. Tests for the significance $(\alpha=0.05)$ of these values were made by generating 1000 pseudoreplicate datasets and using these as a null distribution to see how likely it was that the $\Phi_{\text {st }}$ result arose by chance. A Bonferroni correction $(\alpha=\alpha / \mathrm{m}=0.05 / 6=0.0083)$ was applied to the significance calculations to reduce the chance of making false positive observations (Everitt, 1998).

\section{Results}

\section{SSCP scoring and sequencing}

An example of the SSCP patterns produced by the experimental protocol described above is shown in Figure 1. In nine of the 232 individuals assayed by SSCP, the RsaI site had been lost through mutation. This was confirmed by sequencing and the haplotype sequences were included in the final analysis. Ten polymorphisms were identified for the smaller (303 bp) of the two COI fragments (Figure 2). Sequencing of these SSCPs and loss of RsaI site haplotypes (Genbank accession numbers AF444799-AF444817) revealed 15 variable nucleotides in this region. Nineteen polymorphisms of the larger (362 bp) of the two COI 


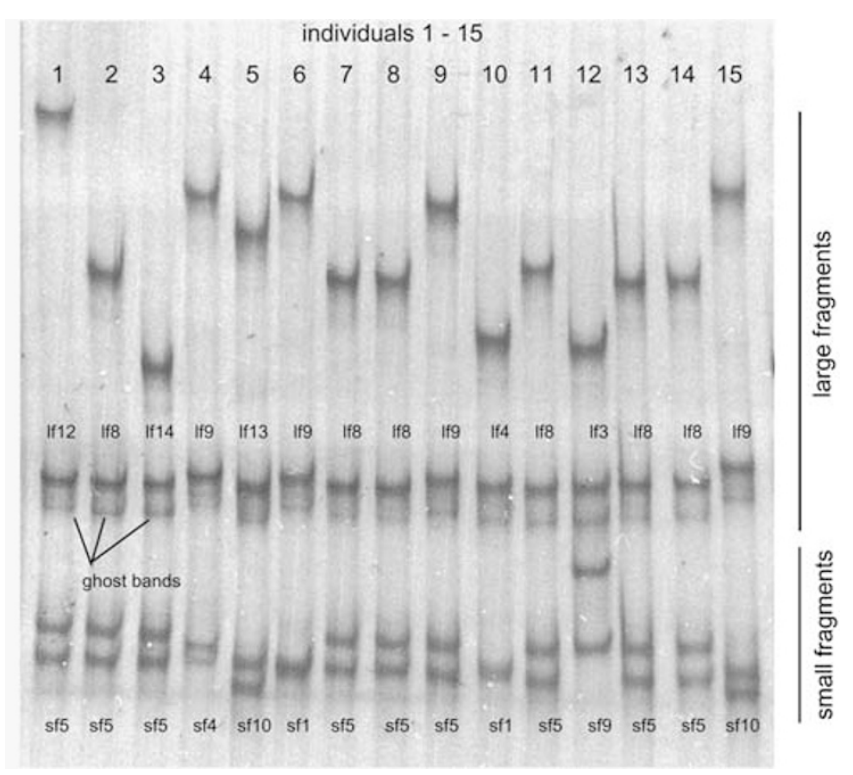

Figure 1 A portion of a typical SSCP gel of mitochondrial COI DNA from Euphausia crystallorophias. Each fragment of the COI region has two bands that migrate at different rates in each SSCP. The faster moving of the large fragment bands always had a 'ghost band' that migrated just ahead of the main band. This artefact was consistently present in all haplotypes and did not affect scoring. Each small fragment and large fragment SSCP was given a number (sf1-10 and 1f1-19). These SSCPs are summarised in Figure 2. SSCPs were assigned to DNA sequences by sequencing the COI region in one or more individuals and assuming that other individuals with the same SSCP had the same DNA sequence. For example, sequencing of the COI region of individual 2 on this gel allows the small fragment DNA sequence sf5 to be also assigned to individuals 1 , $2,3,7,8,9,11,13$ and 14 . The large fragment DNA sequence for individual 2 could also be applied to individuals 7, 8, 11, 13 and 14 .

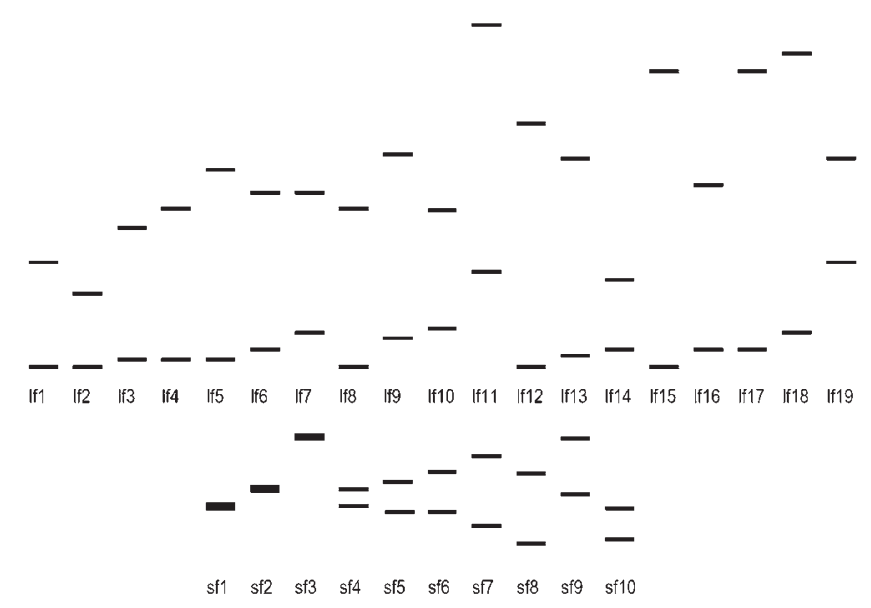

Figure 2 All SSCPs identified in this study. The thicker bands for sf1, sf2 and sf3 represent the comigration of both small fragment strands, producing a single band on the gel. An example of this is shown in Figure 1 where lanes 6 and 10 were scored as sf1.

fragments were observed (Figure 2). Sequencing of the corresponding fragments and loss of RsaI site haplotypes demonstrated that the SSCPs were caused by different combinations of 23 variable sites in this region (Genbank accession numbers AF444818-AF444845). 82 compound haplotypes for the whole $665 \mathrm{bp}$ region of the $5^{\prime}$ end of the COI cistron resulted from various combinations of haplotypes for the 303 and 362 bp fragment haplotypes. The frequencies of occurrence of each COI haplotype in each population are shown in Table 1.

Most haplotypes were sequenced more than twice. All sequences were primed from the undigested $665 \mathrm{bp}$ COI region. This meant that each time a novel small fragment haplotype was sequenced, a large fragment haplotype was also sequenced or vice versa. No undetected mutations were discovered by sequencing the haplotypes for different individuals with the same SSCP. However, two small fragment SSCPs that had been scored as different in some cases turned out to have had the same sequence. In retrospect, the gel distinction between the two did seem minor and they were treated as the same haplotype (sf1, Figure 2).

\section{Tests for selective neutrality}

The majority of the 38 variable sites identified by alignment of the COI sequences did not affect the COI protein sequence and can be assumed to be selectively neutral. However, there were four variable sites that did alter the translation of this region if we assume that krill use the same mitochondrial genetic code as Drosophila melanogaster. Tajima's (Table 2) and Ewens-Watterson's (Table 3) neutrality tests were applied to the haplotype frequency data to see whether any of the haplotypes were potentially responsible for a change in fitness.

Tajima's test found no significant $(\alpha=0.05)$ departures from haplotype frequencies expected by chance, based on an infinite sites model. All calculations of Tajima's D, including that for the pooled data from all populations, gave a negative value.

The Ewens-Watterson test did reveal significant departure from expected haplotype frequencies based on an infinite allele models in both the M.G. Polynya samples and in the combined data. It is therefore possible that some of the haplotypes have selective effects. There were 82 haplotypes in only 232 individuals in this study and many of the haplotypes are only represented at low levels (Table 1), so it is possible that these under-represented haplotypes have mild selective effects that wouldn't be apparent if the study used larger sample sizes.

\section{Analysis of molecular variance}

An appropriate model of DNA evolution was chosen after maximum likelihood estimation of several parameters for the COI region. The estimated equilibrium base frequencies of the COI dataset (A: 0.271, C: 0.213 , G: 0.185 , T: 0.331) demonstrated that they were not even approximately equal ( 0.25 each). Estimation of the rates of different substitution types found that $\mathrm{G}-\mathrm{A}$ transitions were $\sim 22$ times more common than G-T transversions and that $\mathrm{C}-\mathrm{T}$ transitions were $\sim 10$ times more common than G-T transversions. These large differences in transition and transversion rates and a clear difference between rates of different transitions suggested that the Tamura and Nei (1993) model of DNA substitution would be appropriate as it can account for these differences. Extensive differences in substitution rates between sites were found, with the $\alpha$ parameter of a discrete gamma distribution with eight rate categories estimated to be 0.051 . The results of AMOVA under the Tamura and Nei (1993) model with gamma correction applied with an $\alpha$ value of 0.051 are shown in Table 4 .

Although this test demonstrated that the majority of 
Table 1 COI haplotype frequencies: 82 different haplotypes for a 665-bp region of the mitochondrial COI region in Euphausia crystallorophias. Most of these haplotypes were identified by SSCPs for two parts of the COI. Nine individuals had lost the RSA I recognition site that allowed this assay, so their haplotypes were found by direct sequencing

\begin{tabular}{|c|c|c|c|c|c|}
\hline $\begin{array}{l}\text { Small } \\
\text { fragment }\end{array}$ & $\begin{array}{c}\text { Large } \\
\text { fragment }\end{array}$ & $\begin{array}{c}\text { W.A. } \\
\text { Peninsula }\end{array}$ & $\begin{array}{c}\text { Davis } \\
\text { Sea }\end{array}$ & $\begin{array}{c}\text { M.G. } \\
\text { Polynya } \\
A\end{array}$ & $\begin{array}{c}\text { M.G. } \\
\text { Polynya } \\
B\end{array}$ \\
\hline
\end{tabular}

\begin{tabular}{llllllll}
\hline sf01 & lf02 & 4 & 1 & 0 & 0 & 5 & sf08 \\
sf01 & lf03 & 1 & 3 & 0 & 2 & 6 & sf09 \\
sf01 & lf04 & 0 & 1 & 1 & 0 & 2 & sf10 \\
sf01 & lf05 & 3 & 1 & 2 & 1 & 7 & sf10 \\
sf01 & lf06 & 0 & 2 & 1 & 2 & 5 & sf10
\end{tabular}

Table 1 Continued

\begin{tabular}{lcccccc}
\hline $\begin{array}{l}\text { Small } \\
\text { fragment }\end{array}$ & $\begin{array}{c}\text { Large } \\
\text { fragment }\end{array}$ & $\begin{array}{c}\text { W.A. } \\
\text { Peninsula }\end{array}$ & $\begin{array}{c}\text { Davis } \\
\text { Sea }\end{array}$ & $\begin{array}{c}\text { M.G. } \\
\text { Polynya } \\
\text { A }\end{array}$ & $\begin{array}{c}\text { M.G. } \\
\text { Polynya } \\
B\end{array}$ & Total \\
\hline sf07 & lf05 & 0 & 1 & 0 & 1 & 2 \\
sf07 & lf07 & 0 & 1 & 0 & 0 & 1 \\
sf07 & lf08 & 0 & 1 & 0 & 0 & 1 \\
sf08 & lf04 & 0 & 1 & 0 & 0 & 1 \\
sf08 & lf15 & 0 & 1 & 0 & 0 & 1 \\
sf09 & lf03 & 0 & 0 & 1 & 0 & 1 \\
sf09 & lf08 & 0 & 1 & 0 & 0 & 1 \\
sf10 & lf03 & 0 & 0 & 0 & 1 & 1 \\
sf10 & lf04 & 0 & 0 & 0 & 1 & 1 \\
sf10 & lf09 & 0 & 0 & 0 & 1 & 1
\end{tabular}

Loss of RsaI site haplotype

Davis Sea 1

Davis Sea 2

Davis Sea 3

Davis Sea 4

Davis Sea 5

Davis Sea 6

M.G. Polynya A 1

M.G. Polynya A 2

M.G. Polynya B 1

0
0
0
0
0
0
0
0
0

$\begin{array}{llll}1 & 0 & 0 & 1 \\ 1 & 0 & 0 & 1 \\ 1 & 0 & 0 & 1 \\ 1 & 0 & 0 & 1 \\ 1 & 0 & 0 & 1 \\ 1 & 0 & 0 & 1 \\ 0 & 1 & 0 & 1 \\ 0 & 1 & 0 & 1 \\ 0 & 0 & 1 & 1\end{array}$

genetic variation between individuals could be explained by within sample differences, a significant portion $(3.68 \%)$ was found to be due to between sample differences. The null hypothesis of unrestricted gene flow between the populations we sampled was rejected with a value of $P<0.001$ based on a comparison of this $\Phi_{\mathrm{ST}}$ with calculations of $\Phi_{\mathrm{ST}}$ for 1000 pseudoreplicate datasets. Having established that there were significant differences in haplotype frequencies between all the samples, we then made pairwise $\Phi_{\mathrm{ST}}$ calculations to find how each sample contributed to the overall genetic structure.

\section{Pairwise $\Phi_{\text {st }}$ calculation}

$\Phi_{\text {st }}$ values for assessing the extent of genetic differentiation between pairs of krill samples were calculated under the same model of DNA evolution as used for the AMOVA above. Significance tests for these calculations based on a null distribution of $\Phi_{\text {st }}$ values created from 1000 psudoreplicate datasets are given in Table 5. Pairwise $\Phi_{\text {st }}$ values shown to be significant are given with the sampling sites on Figure 3. These pairwise tests show that the majority of the genetic differentiation between samples is caused by sample M.G. Polynya B, which is significantly different from the other three samples. M.G. Polynya A also shows differentiation from the Davis Sea sample. The Bonferroni correction is considered a conservative correction for multiple pairwise comparisons, especially when the number of comparisons is greater than five (Everitt, 1998). In this case, where the number of comparisons $\mathrm{m}=6$, Bonferroni correction only just brings the $P$ value for the comparison between M.G. Polynya 1 and Davis Sea into the non-significant range. We therefore consider the significance of this genetic differentiation to be equivocal.

\section{Discussion}

This study demonstrated that there is genetic differentiation between different samples of E. crystallorophias. A 
Table 2 Results of Tajima's test of selective neutrality applied to mtDNA COI haplotype distribution in four populations of Euphausia crystallorophias and the pooled data from all populations

\begin{tabular}{|c|c|c|c|c|c|}
\hline & W.A. Peninsula & Davis Sea & M.G. Polynya A & M.G. Polynya B & All samples \\
\hline No. of genes in sample & 61 & 65 & 59 & 47 & 232 \\
\hline No. of haplotypes in sample & 31 & 37 & 31 & 28 & 82 \\
\hline Observed $F$ value & 0.05724 & 0.04663 & 0.06751 & 0.07379 & 0.01501 \\
\hline Expected F value & 0.04647 & 0.04039 & 0.05005 & 0.05343 & 0.01207 \\
\hline No. of simulated samples & 1000 & 1000 & 1000 & 1000 & 1000 \\
\hline Watterson F P value & 0.071 & 0.097 & $0.034^{*}$ & $0.018^{*}$ & $0.019 *$ \\
\hline
\end{tabular}

Table 3 Results of Ewens-Watterson's test of selective neutrality applied to mtDNA COI haplotype variation in four populations of Euphausia crystallorophias and the pooled data from all populations

\begin{tabular}{lccccc}
\hline & W.A. Peninsula & Davis Sea & M.G. Polynya A & M.G. Polynya B & All samples \\
\hline Sample size & 61 & 65 & 59 & 47 & 232 \\
No. of sites with substitutions & 23 & 36 & 34 & 38 & 5.19899 \\
Mean No. of pairwise differences & 4.55191 & 5.44567 & 4.71654 & 5.56337 & -0.88543 \\
Tajima's D & -0.23233 & -0.92069 & -1.16821 & -0.040858 & -0.1960 \\
$P$ value & 0.42914 & 0.18903 & 0.12370 & 0.36226 & \\
\hline
\end{tabular}

* Indicates significance at $\alpha=0.05$.

Table 4 Analysis of molecular variance for mtDNA COI haplotype variation in four populations of Euphausia crystallorophias

\begin{tabular}{lcccc}
\hline Source of variation & d.f. & Sum of squares & Variance components & Percentage of variation \\
\hline Among samples & 3 & 30.109 & 0.11964 (among samples) & $3.68 \%$ \\
Within samples & 228 & 713.186 & 3.12801 (within samples) & $96.32 \%$ \\
Total & 231 & 743.295 & 3.24765 & \\
Fixation Index $\Phi_{\text {ST }}: 0.03684$ & & & &
\end{tabular}

Table 5 Significance tests for six pairwise $\Phi_{\text {st }}$ calculations between the four populations of Euphausia crystallorophias used in this study

\begin{tabular}{lccc}
\hline & M.G. Polynya B & M.G. Polynya A & Davis Sea \\
\hline W.A. Peninsula & $0.00195 \pm 0.0014^{\mathrm{a}, \mathrm{b}}$ & $0.52051 \pm 0.0150$ & $0.05078 \pm 0.0049$ \\
Davis Sea & $0.00000 \pm 0.0000^{\mathrm{a}, \mathrm{b}}$ & $0.01074 \pm 0.0039^{\mathrm{a}}$ & - \\
M.G. Polynya A & $0.00293 \pm 0.0016^{\mathrm{a}, \mathrm{b}}$ & - & - \\
\hline
\end{tabular}

aSignificant at $\alpha=0.05$ without Bonferroni correction. 'bignificant at $\alpha=0.0083$ with Bonferroni correction.

significant proportion of the variation in mtDNA COI haplotypes resulted from differences between populations, allowing a null hypothesis of panmixia in E. crystallorophias to be rejected. This finding contrasts with that of Kühl and Schneppenheim (1985) who found the frequency of allozymes in various E. crystallorophias populations to be homogeneous. Other studies of krill population genetics using mtDNA data have also demonstrated genetic differentiation where none was previously discovered with allozyme studies (Bucklin et al, 1997; Zane et al, 1998, 1999). The greater sensitivity of mtDNA variation to population genetic structure is likely to result from the higher evolutionary rate of these COI sites and smaller effective population size of the mitochondrial DNA. Animal mitochondrial genomes are haploid and are almost always inherited maternally, decreasing the effective population size of mtDNA markers to $1 / 4$ that of nuclear markers (Avise, 1994). This increases the stochastic effects of random mating on allele frequencies relative to this effect on nuclear DNA markers such as allozymes (Karl et al, 1992). Most of the mutations found in the COI region did not affect the translation of that region into protein, whereas the mutations identified by allozymes must alter protein sequence so that allozyme frequencies may become more stable as result of balancing selection and new alleles are less likely to be generated (Karl and Avise, 1992).

The extent of genetic differentiation observed between krill samples is related neither to degree of geographic separation between samples or to any obvious oceanographic feature. The major source of differentiation is the sample M.G. Polynya B, which is separated from M.G. Polynya A by only 16 km, from Davis Sea by $>1000 \mathrm{~km}$ and from W.A. Peninsula by $>6000 \mathrm{~km}$ (Figure 3). In fact, 


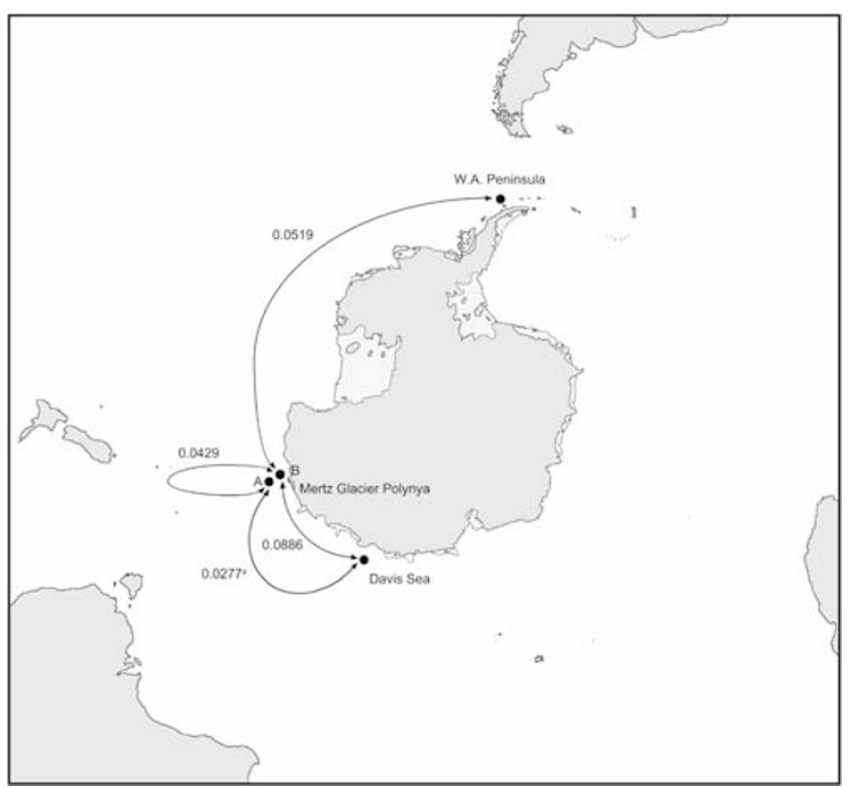

Figure 3 Antarctic and the Southern Ocean with sampling sites indicated. Significant $(\alpha=0.05)$ pairwise $\Phi_{\mathrm{st}}$ values found between four samples of Euphausia crystallorophias. \#The difference between M.G. Polynya 1 and Davis Sea was not significant with Bonferroni correction $(\alpha=0.0083)$.

the two most widely separated samples, W.A. Peninsula and Davis Sea show no significant pairwise $\Phi_{\text {st }}$ difference. M.G. Polynya A and M.G. Polynya B also had significant departures from allele frequencies expected in a population unaffected by selection in the Ewens-Watterson test. It is possible that differences in the frequency of alleles that had different COI protein sequences had selective effects. However, perhaps a more likely explanation is that a recent population expansion has occurred in either or both of the M.G. Polynya populations. Similar observations of apparent deviation from selective neutrality under the infinite alleles model of the Ewens-Watterson test have been made in E. superba (Zane et al, 1998), which is a close relative of E. crystallorophias (Patarnello et al, 1996; Jarman et al, 2000). Zane et al (1998) attributed this finding in E. superba to the effects of a recent population expansion, based on the idea of Rogers and Harpending (1992). The negative values of Tajima's D found for all populations and for the combined data may also be an indication of recent population expansion events rather than selective effects (Aris-Brosou and Excoffier, 1996).

The identification of genetic differentiation between samples taken from very close sites suggests that genetic differentiation between swarms may be an important cause of intraspecific genetic differentiation in krill, rather than the effects of large-scale oceanographic features. This would be consistent with observations of significant biological differences between swarms of $E$. superba (Fevolden and George, 1984; Quentin and Ross, 1984; and Watkins et al, 1986, 1990). In order to distinguish between genetic differentiation between regions and between swarms, numerous within-region (between swarm) comparisons and between-region comparisons would have to be made. This study was originally conceived under the same assumption of previous studies of krill population genetics: that genetic differentiation in krill would be primarily due to large-scale geographic factors. Our inclusion of two populations from one geographic region provides preliminary evidence that this assumption is incorrect.

Swarming behaviour and differences in biological characteristics between swarms have been recorded in other krill species such as E. superba (Quentin and Ross, 1984; Watkins et al, 1990) and Meganyctiphanes norvegica (Nicol, 1984). Differences between swarms are likely to also occur in E. crystallorophias and may be the cause of the genetic differentiation identified here. As individual krill tend to be more like other individuals caught in the same net tow than krill caught in different net tows for length and apparent maturity, it is possible that swarms are associations persisting for large parts of the lifespan of their members. As a result of this, swarms may represent associations of krill that are more related to each other than to individuals from other swarms. Genetic differentiation between krill swarms within one region could then represent temporary fluctuations around regional (or species) averages beyond those expected from sampling error.

The possibility that genetic differentiation occurs between nearby krill swarms needs to be tested further. This has implications for the design of future experiments for studying krill population genetics. These experiments should attempt to distinguish between large-scale and small-scale barriers to gene flow. Ideally several samples would be taken from each separate region so that differentiation between swarms can be distinguished from differentiation between regions. It would also be helpful to analyse several samples taken from within one swarm to check the power of the genetic analysis. As our work suggests that there is genetic differentiation between swarms of krill, geographic differentiation between krill caught in separate regions should be studied with the potential barriers to gene flow clearly identified as a prior hypothesis, rather than the barriers being inferred after a null hypothesis of panmixia is disproven.

\section{Acknowledgements}

Thanks to Langdon Quentin and Robyn Ross for the sample of Euphausia crystallorophias from the west side of the Antarctic Peninsula. Bob Ward, Brad Evans and Chester Sands provided constructive criticism of the manuscript.

\section{References}

Ainley, DG, Wilson PR, Barton KJ, Ballard G, Nur N, Karl B (1998). Diet and foraging effort of Adelie penguins in relation to pack-ice conditions in the southern Ross Sea. Polar Biol 20: 311-319.

Aris-Brosou S, Excoffier L (1996). The impact of population expansion and mutation rate heterogeneity on DNA sequence polymorphism. Mol Biol Evol 13: 494-504.

Ausubel FM, Brent R, Kingston RE, Moore DP, Seidman JG, Smith JA, Struhl K (1997). Current Protocols in Molecular Biology, Wiley Interscience: New York. pp 2.2.3.

Avise JC (1994). Molecular Markers, Natural History and Evolution, Chapman and Hall: New York. p 34.

Bowtell DDL (1987). Rapid isolation of eukaryotic DNA. Anal Biochem 162: 463-465.

Bucklin A, Smolenack SB, Bentley AM, Wiebe PH (1997). Gene flow patterns of the euphausiid, Meganyctiphanes norvegica, in the NW Atlantic based on mtDNA sequences for cytochrome $\mathrm{B}$ and cytochrome oxidase I. J Plankton Res 19: 1763-1781. 
Chomczynski P, Mackey K, Drews R, Wilfinger W (1997). DNAzol ${ }^{\circledR}$ : a reagent for the rapid isolation of genomic DNA. Biotechniques 22: 550-553

Everitt BS (1998). The Cambridge Dictionary of Statistics. Cambridge University Press: Cambridge, UK.

Ewens WJ (1972). The sampling theory of selectively neutral alleles. Theor Popul Biol 3: 87-102.

Excoffier L, Smouse P, Quattro J (1992). Analysis of molecular variance inferred from metric distances among DNA haplotypes: application to human mitochondrial DNA restriction data. Genetics 131: 479-491.

Fang G, Hammar S, Grummet R (1992). A quick and inexpensive method for removing polysaccharides from plant DNA. Biotechniques 13: 52-56.

Felsenstein J (1981). Evolutionary trees from DNA sequences: a maximum likelihood approach. J Mol Evol 17: 368-376.

Fevolden SE, Ayala FJ (1981). Enzyme polymorphism in Antarctic krill (Euphausiacea): genetic variation between populations and species. Sarsia 66: 167-181.

Fevolden SE, George RY (1984). Size frequency pattern of Euphausia superba in the Antarctic Peninsula waters in the austral summer of (1983). J Crust Biol 4: 107-122.

Fevolden SE, Schneppenheim R (1989). Genetic homogeneity of krill (Euphausia superba Dana) in the Southern Ocean. Polar Biol 9: 533-539.

Folmer O, Black M, Hoeh W, Lutz R, Vrijenhoek R (1994). DNA primers for amplification of mitochondrial cytochrome c oxidase subunit I from diverse metazoan invertebrates. Mol Mar Biol Biotech 3: 294-299.

Hongyo T, Buzard GS, Calvert RJ, Weghorst CM (1993). Cold SSCP - a simple rapid and non-radioactive method for optimized single strand conformational polymorphism analyses. Nucleic Acids Res 21: 3637-3642.

Ichii T, Shinohara N, Fujise Y, Nishiwaki S, Matsuoka K (1998). Interannual changes in body fat composition of minke whales in the Antarctic. Mar Ecol Prog Ser 175: 1-12.

Jarman SN, Elliott NG, Nicol S, McMinn A (2000). Molecular phylogenetics of circum-global Euphausia species (Euphausiacea: Crustacea). Can J Fish Aquat Sci 57: (Suppl 3); 51-58.

Karl SA, Avise JC (1992). Balancing selection at allozyme loci in oysters: implications from nuclear RFLPs. Science 256: 100102.

Karl SA, Bowen BW, Avise JC (1992). Global population structure and male-mediated gene flow in the green turtle (Chelonia mydas): RFLP analyses of anonymous nuclear loci. Genetics 131: 163-173

Kühl S, Schneppenheim R (1985). Electrophoretic investigation of genetic variation in two krill species Euphausia superba and E. crystallorophias (Euphausiidae). Polar Biol 6: 17-23.

La Mesa M, Vacchi M, Sertorio TZ (2000). Feeding plasticity of Trematomus newnesi (Pisces, Nototheniidae) in Terra Nova Bay, Ross Sea, in relation to environmental conditions. Polar Biol 23: 38-45.

Macdonald CM, Williams R, Adams M (1986). Genetic variation and population structure of krill (Euphausia superba Dana) from the Prydz Bay region of Antarctic waters. Polar Biol 6: 233-236.

Mauchline J, Fisher LR (1969). The biology of euphausiids. Advances in Marine Biology 7: Academic Press: London.

Melnikov IA, Spiridinov VA (1996). Antarctic krill under perrenial sea ice in the western Weddel Sea. Antarct Sci 8: 323-329.

Miller SA, Dykes DD, Polesky HF (1988). A simple salting out procedure for extracting DNA from human nucleated cells. Nucleic Acids Res, 16: 1215.

Nicol S (1984). Population structure of daytime surface swarms of the euphausiid Meganyctiphanes norvegica in the Bay of Fundy. Mar Ecol Prog Ser 18: 241-251.

Orita M, Iwahana H, Kanazawa H, Hayashi K, Sekiya T (1989).
Detection of polymorphisms of human DNA by gel electrophoresis as single strand polymorphisms. Proc Natl Acad Sci USA 86: 2766-2770.

Packhamov EA, Perissinotto R (1996). Antarctic neritic krill Euphausia crystallorophias: spatio-temporal distribution, growth and grazing rates. Deep Sea Res Pt I 43: 59-87.

Patarnello T, Bargelloni L, Varotto V, Battaglia B (1996). Krill evolution and the Antarctic ocean currents: evidence of vicariant speciation as inferred by molecular data. Mar Biol 126: 603-608.

Quentin LB, Ross RM (1984). School composition of the Antarctic krill Euphausia superba in the waters west of the Antarctic Peninsula in the Austral summer of 1982. J Crust Biol 4: 96106.

Reid K, Watkins JL, Croxall JP, Murphy EJ (1999). Krill population dynamics at South Georgia 1991-1997, based on data from predators and nets. Mar Ecol Prog Ser 177: 103-114.

Rogers AR, Harpending H (1992). Population growth makes waves in the distribution of pairwise genetic differences. $\mathrm{Mol}$ Biol Evol 9: 552-569.

Saitou N, Nei M (1987). The neighbour-joining method: a new method for reconstructing phylogenetic trees. Mol Biol Evol 4: 406-425.

Schneider S, Roessli D, Excoffier L (2000). Arlequin ver 2.000: A software for population genetics data analysis. Genetics and Biometry Laboratory: University of Geneva, Switzerland.

Sundt RC, Fevolden SE (1996). Homogeneous genetic structure of Meganyctiphanes norvegica (Euphausiacea) in the north-east Atlantic ocean, as interpreted from allozymic variation. Sarsia 81: 155-159.

Sunnucks P, Wilson ACC, Becheregaray LB, Zenger K, French J, Taylor AC (2000). SSCP is not so difficult: the application and utility of single-stranded conformation polymorphism in evolutionary biology and molecular ecology. Mol Ecol 9: 1699-1710.

Swofford DL (1998). PAUP*. Phylogenetic Analysis Using Parsimony (*and Other Methods). Version 4. Sinauer Associates, Sunderland, Massachusetts.

Tajima F (1989). Statistical method for testing the neutral mutation hypothesis by DNA polymorphism. Genetics 123: 597-601.

Tamura K, Nei M (1993). Estimations of the number of nucleotide substitutions in the control region of mitochondrial DNA in humans and chimpanzees. Mol Biol Evol 10: 512-516.

Thomas PG, Green K (1988). Distribution of Euphausia crystallorophias within Prydz Bay and its importance to the inshore marine ecosystem. Polar Biol 8: 327-331.

Watkins JL, Morris DJ, Ricketts C, Priddle J (1986). Differences between swarms of Antarctic krill and some implications for sampling krill populations. Mar Biol 93: 137-146.

Watkins JL, Morris DJ, Ricketts C, Murray AWA (1990). Sampling biological characteristics of krill: effects of heterogeneous nature of swarms. Mar Biol 107: 409-415.

Watterson G (1978). The homozygosity test of neutrality. Genetics 88: 405-417.

Wienecke BC, Lawless R, Rodary D, Bost CA, Thomson R, Pauly $\mathrm{T}$ et al. (2000). Adelie penguin foraging behaviour and krill abundance along the Wilkes and Adelie land coasts, Antarctica. Deep Sea Res Pt II 47: 2573-2587.

Yang Z (1994). Maximum likelihood estimation from DNA sequences with variable rates over sites. J Mol Evol 39: 329324.

Zane L, Ostellari L, Maccatrozzo L, Bargelloni L, Battaglia B, Patarnello T. (1998). Molecular evidence for genetic sudivision of Antarctic krill populations. Proc Roy Soc Lond Ser B 265: 2387-2391.

Zane L, Ostellari L, Maccatrozzo L, Bargelloni L, Cuzin-Roudy J et al. (1999). Genetic differentiation in a pelagic crustacean (Meganyctiphanes norvegica, Euphausiacea) from the North East Atlantic and Mediterranean Sea. Mar Biol 136: 191-199. 